\title{
Genetic and epidemiological analysis of norovirus from children with gastroenteritis in Botswana, 2013-2015
}

Kgomotso Makhaola', Sikhulile Moyo ${ }^{2,3}, K^{1}$ wana Lechiile ${ }^{4}$, David M. Goldfarb ${ }^{4,5}$ and Lemme P. Kebaabetswe ${ }^{\text {* }^{*}}$

\begin{abstract}
Background: Norovirus is a leading cause of viral gastroenteritis worldwide with a peak of disease seen in children. The epidemiological analysis regarding the virus strains in Africa is limited. The first report of norovirus in Botswana was in 2010 and currently, the prevalence and circulating genotypes of norovirus are unknown, as the country has no systems to report the norovirus cases. This study investigated the prevalence, patterns and molecular characteristics of norovirus infections among children $\leq 5$ years of age admitted with acute gastroenteritis at four hospitals in Botswana.

Methods: A total of 484 faecal samples were collected from children who were admitted with acute gastroenteritis during the rotavirus vaccine impact survey between July 2013 and December 2015. Norovirus was detected using realtime RT-PCR. Positive samples were genotyped using conventional RT-PCR followed by partial sequencing of the capsid and RdRp genes. Norovirus strains were determined by nucleotide sequence analysis using the online Norovirus Genotyping Tool Version 1.0, and confirmed using maximum likelihood tree construction as implemented in MEGA 6.0.

Results: The prevalence of norovirus was $9.3 \%$ (95\% Cl 6.7-11.9). The genotype diversity was dominated by the Gll.4 strain at $69.7 \%$. This was followed by GII.2, GIl.12 each at 9.1\%, GI.9 at 6.6\% and GII.6, Gll.10 each at 3.0\%. The most common combined RdRp/Capsid genotype was the Gll.Pe/Gll.4 Sydney 2012. Norovirus was detected during most part of the year; however, there was a preponderance of cases in the wet season (December to March).

Conclusion: The study showed a possible decline of norovirus infections in the last 10 years since the first report. An upward trend seen between 2013 and 2015 may be attributable to the success of rotavirus vaccine introductions in 2012. Knowledge of circulating genotypes, seasonal trends and overall prevalence is critical for prevention programming and possible future vaccine design implications.
\end{abstract}

Keywords: Norovirus, GIl.4 variants, GIl.Pe-Gll.4, Botswana, Genotyping

\section{Background}

Globally, noroviruses are a leading cause of acute gastroenteritis [1]. Its symptoms include nausea, diarrhoea, vomiting, stomach cramps and fever [2]. While these symptoms can be self-limiting in healthy individuals, children, elderly and immune-compromised individuals often experience prolonged symptoms $[3,4]$. The shedding of norovirus has also been shown in asymptomatic individuals [5], and its transmission occurs mainly by the faecal-oral route, through either contaminated food

\footnotetext{
* Correspondence: kebaabetswel@biustac.bw

${ }^{1}$ Department of Biological Sciences and Biotechnology, Botswana

International University of Science and Technology, Private Bag, 16 Palapye,

Botswana

Full list of author information is available at the end of the article
}

or water sources [6], person to person contact or through aerosols [7]. Additionally, norovirus has been shown to have low infectious dose [8]. Currently, there is no antiviral treatment for norovirus infections, and vaccines are in late development stages $[9,10]$. Noroviruses are single stranded, small non-enveloped RNA viruses that belong to the Caliciviridae family [11, 12]. Their genome is approximately $7.5 \mathrm{~kb}$ long and comprises three to four open reading frames (ORF), $[12,13]$. ORF-1 encodes a large polyprotein, which is cleaved by virus-encoded protease, into six non-structural proteins that include the RNA-dependent RNA polymerase (RdRp) [14]. ORF-2, ORF-3 and ORF-4 encode the major capsid protein, VP1, minor structural protein, VP2

(c) The Author(s). 2018 Open Access This article is distributed under the terms of the Creative Commons Attribution 4.0 International License (http://creativecommons.org/licenses/by/4.0/), which permits unrestricted use, distribution, and reproduction in any medium, provided you give appropriate credit to the original author(s) and the source, provide a link to the Creative Commons license, and indicate if changes were made. The Creative Commons Public Domain Dedication waiver (http://creativecommons.org/publicdomain/zero/1.0/) applies to the data made available in this article, unless otherwise stated. 
and virulence factor, respectively. The ORF-4 is unique to the murine norovirus cluster $[6,8,14]$. When using complete amino acid sequences of the capsid protein, noroviruses cluster into seven genogroups [10, 15], and each genogroup is subdivided into several genotypes. While genogroups I, II and IV have been shown to infect humans [5, 8], GII.4 is the predominant genotype globally, and every few years new GII.4 variants surface that rapidly replace the dominant circulating strain [16]. Several factors have been suggested that enable this strain to dominate infections and these are: high mutation rates, wide receptor specificity, and short-term immunity compared to other strains $[2,6]$. Routinely, the norovirus genotype determination is by either the partial capsid or RdRp gene sequences. However, noroviruses being RNA viruses undergo recombination at ORF1/ORF2 that leads to a single virus strain clustering under different genotypes when different genomic regions are used for sequencing $[8,17,18]$. Based on these, there is need to determine both the capsid and RdRp genotypes.

In most of Sub-Saharan Africa, routine norovirus surveillance is lacking or limited. Prevalence of norovirus in Africa among symptomatic children is estimated at $13.5 \%(95 \% \mathrm{CI} 0.8-25.5)$ and among the asymptomatic at $9.7 \%(95 \%$ CI $7-31 \%)$ [10]. A previous study in Botswana has estimated norovirus prevalence at $24 \%$ [19] among symptomatic children. Following multiple gastroenteritis outbreaks that claimed many lives, the rotavirus vaccine was introduced in Botswana in July 2012 [20, 21]. While this move has significantly reduced cases and deaths related to gastroenteritis [22], understanding the causative agents of the remaining gastroenteritis cases is critical for prevention and management. Studies report that where rotavirus vaccine is used on a large scale, norovirus infections become significant [23]. It is therefore critical to understand norovirus infections in Botswana after a large scale-up of the rotavirus vaccine. In this study, we determined the prevalence, genetic diversity and trends of norovirus infections among children 5 years and younger admitted with acute gastroenteritis in Botswana between 2013 and 2015.

\section{Methods}

\section{Study population and setting}

Between July 2013 and December 2015, faecal samples were collected from children under 5 years admitted with acute gastroenteritis at four health facilities in Botswana (Princess Marina Hospital, Nyangabgwe Referral Hospital, Letsholathebe II Memorial Hospital and Bobonong Hospital), as part of the National Surveillance on Rotavirus Vaccine Impact Survey 2012-
2015 [22]. The facilities represent geographical regions where more than $80 \%$ of Botswana's population resides.

\section{Sample collection and preparation}

Bulk stool $(\sim 5 \mathrm{ml})$ or flocked rectal swab was obtained from each participant within $48 \mathrm{~h}$ of hospitalization to avoid detection of hospital-acquired infections. All samples were transported to the National Health Laboratory on ice and kept at $-80{ }^{\circ} \mathrm{C}$ until testing. A $10 \%$ stool suspension was prepared using Precellys ${ }^{\oplus}$ Lysing kit (Bertin Corp, Rockville, MD), according to the manufacturer's instructions. The supernatant was then stored at $-80{ }^{\circ} \mathrm{C}$ prior to nucleic acid extraction.

\section{RNA extraction and viral detection}

Norovirus was detected using multiplex real-time PCR as described previously [24]. Briefly, total nucleic acid extraction was performed using easyMag (bioMerieux, Lyon, France). $200 \mu \mathrm{l}$ of the supernatant was used to yield a nucleic acid elution volume of $70 \mu \mathrm{l}$. Norovirus GI/GII was detected using the viral multiplex panel and qualitative real-time PCR with the ABI 7500 Fast (Applied Biosystems, Carlsbad, CA, USA). The samples were taken through 45 PCR cycles. Targets with Cycle threshold $(\mathrm{Ct})$ values below 40 were considered positive for that particular sample. For quality check, there were three controls included in every batch of testing in the assay: extraction negative control, in-house positive control, and master mix/reagent negative control. The extraction negative control was used to ensure adequate extraction process; the in-house positive control was used to ensure detection of all available targets in the assay; master mix/reagent negative control was used to ensure there was no contamination in master mix preparation.

\section{Capsid and RdRp gene amplification}

Following norovirus detection, positive samples were tested by conventional RT-PCR using the Transcriptor One-Step RT PCR Kit (Roche Diagnostics, Mannheim, Germany). The capsid gene (5' end, region $C$ ) was amplified with oligonucleotide primer sets G1SKF/R and G2SKF/R to amplify the 329 bp of GI and 342 bp GII capsid genes respectively, as previously described [25]. Each $50 \mu \mathrm{l}$ reaction mixture contained $1 \mu \mathrm{l}$ of each primer, $1 \mu \mathrm{l}$ Taq DNA polymerase and $5 \mu \mathrm{l}$ of cDNA. The PCR was performed under these conditions: $50{ }^{\circ} \mathrm{C}$ for $30 \mathrm{~min}, 94{ }^{\circ} \mathrm{C}$ for $10 \mathrm{~min}$ followed by 40 cycles, $94{ }^{\circ} \mathrm{C}$ for $30 \mathrm{~s}, 50{ }^{\circ} \mathrm{C}$ for $30 \mathrm{~s}, 72{ }^{\circ} \mathrm{C}$ for $1 \mathrm{~min}$ and final extension at $72{ }^{\circ} \mathrm{C}$ for $5 \mathrm{~min}$. The $\mathrm{RdRp}$ gene was amplified using published oligonucleotide primer set, JV12/JV13 [26]. The reactions conditions were as follows: Each $50 \mu$ reaction mixture, contained $2 \mu \mathrm{l}$ each primer, $1 \mu \mathrm{l}$ Taq polymerase and $15 \mu \mathrm{l}$ of cDNA. PCR conditions 
were $50{ }^{\circ} \mathrm{C}$ for $30 \mathrm{~min}, 94{ }^{\circ} \mathrm{C}$ for $10 \mathrm{~min}$ followed by 40 cycles $95{ }^{\circ} \mathrm{C}$ for $30 \mathrm{~s}, 37^{\circ} \mathrm{C}$ for $90 \mathrm{~s}$, and $72{ }^{\circ} \mathrm{C}$ for $2 \mathrm{~min}$ and final extension of $5 \mathrm{~min}$. The PCR products were visualised on agarose gel.

\section{Sequencing and phylogenetic analysis}

The amplicons from the partial gene regions for the RdRp and capsid were purified using QIAquick PCR Purification Kit (Qiagen Inc., Valencia, CA), nucleotide sequencing was done using BigDye ${ }^{\oplus}$ Terminator v3.1 Cycle Sequencing Kit (Applied Biosystems, Carlsbad, CA) on 3130 DNA genetic analyser (Applied Biosystems, Carlsbad, CA). Sequencing was done in both directions using same specific primers used for RT-PCR. Sequences were edited using Sequencher ${ }^{\bullet}$ version 5.4.6 DNA sequence analysis software, Gene Codes Corporation, Ann Arbor, MI USA http://www.genecodes.com and norovirus strains were determined by nucleotide sequence analysis using the online Norovirus Genotyping Tool Version 1.0 [27] available at www.rivm.nl/mpf/norovirus/typingtool and confirmed using maximum likelihood method based on the Kimura 2-parameter model as implemented in Molecular Evolutionary Genetic Analysis (MEGA) software version 6.0 [28]. Robustness of the trees was assessed using bootstrap analysis of 1000 replicates. The sequences generated have been submitted to GenBank. Accession numbers for RdRp gene sequences are MF817977 to MF818009 and for capsid gene sequences the accessions numbers are MF920449.1 to MF920478.1. The GII.4 strains that were unidentified using the Norovirus Genotyping tool were identified using the online NCBI databases (https://blast.ncbi.nlm.nih.gov).

\section{Statistical analysis}

Categorical variables and proportions were compared using a two-sided Chi-square or Fisher's exact test where appropriate. Ninety-five confidence intervals (95\% CI) were estimated using the binomial exact method and $P$-value of $<0.05$ was considered statistically significant.

\section{Results}

\section{Clinical and epidemiological data}

Clinical and epidemiological data are given in Table 1. From July 2013 to December 2015 a total of 484 participants were enrolled in the study, 269 (55.6\%) males and $215(44.6 \%)$ females. The median age was 9 months (Q1, Q3: 6, 14; range 1 to 56 months). Participants were enrolled from the following hospitals as follows Princess Marina, 255 (53\%); Nyangabgwe Referral, 112 (23\%); Letsholathebe II Memorial, 83 (17\%) and Bobonong, 32 (7\%).
Table 1 Demographic and clinical characteristics of a study conducted in children with gastroenteritis in Botswana, 2013-2015

\begin{tabular}{|c|c|c|c|}
\hline Characteristic & $\begin{array}{l}\text { Total } \\
\text { Tested }\end{array}$ & $\begin{array}{l}\text { No. of norovirus } \\
\text { Positive (\%) }\end{array}$ & $\begin{array}{l}\text { No. of norovirus } \\
\text { negative (\%) }\end{array}$ \\
\hline \multicolumn{4}{|l|}{ Gender, $n=484$} \\
\hline Males & 269 & $26(9.7)$ & $243(90.3)$ \\
\hline Females & 215 & $19(8.8)$ & $196(91.2)$ \\
\hline \multicolumn{4}{|c|}{ Age (months), $n=484$ (43 missing age) } \\
\hline 0 to 6 & 129 & $14(10.9)$ & $115(89.1)$ \\
\hline 7 to 12 & 166 & $24(14.5)$ & $142(85.5)$ \\
\hline 13 to 18 & 80 & $5(6.2)$ & $75(93.8)$ \\
\hline$>19$ & 66 & 0 & $66(100)$ \\
\hline \multicolumn{4}{|c|}{ Facility, $n=484$ ( 2 unknown facility) } \\
\hline Princess Marina Hospital & 255 & $28(11)$ & $227(89)$ \\
\hline $\begin{array}{l}\text { Nyangabgwe Referral } \\
\text { Hospital }\end{array}$ & 112 & $11(9.8)$ & $101(90.2)$ \\
\hline $\begin{array}{l}\text { Letsholathebe II Memorial } \\
\text { Hospital }\end{array}$ & 83 & $3(3.6)$ & $80(96.4)$ \\
\hline Bobonong Hospital & 32 & $3(9.4)$ & 29 (90.6) \\
\hline \multicolumn{4}{|l|}{ Year, $n=484$} \\
\hline 2013 & 243 & $22(9.1)$ & $221(90.9)$ \\
\hline 2014 & 141 & $10(7.1)$ & $131(92.9)$ \\
\hline 2015 & 100 & $13(13.0)$ & $87(87)$ \\
\hline \multicolumn{4}{|c|}{ Symptoms, $n=484$ (14 missing symptoms) } \\
\hline Diarrhoea and vomiting & 360 & $30(8.3)$ & $330(91.7)$ \\
\hline Diarrhoea only & 62 & $6(9.7)$ & $56(90.3)$ \\
\hline Vomiting only & 48 & $6(12.5)$ & $42(87.5)$ \\
\hline
\end{tabular}

\section{Norovirus prevalence}

The results for the norovirus prevalence are given in Table 1. Of the 484 participants, 45 were positive, 9.3\% (95\% CI 6.7-11.9). The prevalence for 2013, 2014 and 2015 were $9.1 \%(22 / 243), 7.1 \%(10 / 141)$ and $13.0 \%(13 / 100)$, respectively. The prevalence rates for 0-6 months, 7-12 months and 13 to 18 months were $10.9 \%(14 / 129), 14.5 \%(24 / 166)$ and $6.3 \%(5 / 80)$, respectively and these were not statistically different. There were no norovirus infections detected in the months of April, June and November for all the three years of the study. However, the infections were more likely to occur in the wet than in the dry months, $(\mathrm{OR}=3.4 ; 95 \%$ CI 1.31-8.81). Diarrhoea was associated with vomiting symptoms, 360/470 (83\%) (Fisher's exact $p=0.001$ ) and the majority of norovirus positive children presented with vomiting and diarrhoea, 30/ $45(67 \%)$.

\section{Norovirus genotyping}

From 45 positive norovirus samples, 33 (73.3\%) were genotyped. Norovirus geno-grouping revealed that GII 
was most prevalent $93.9 \%(31 / 33)$ followed by GI at $6.1 \%,(2 / 33)$. In total 6 RdRp-based (33 samples) and 5 capsid-based (30 samples) genotypes were identified in GII geno-group as represented in Fig. 1a and b. Based on the capsid gene, the GII.4 strain was predominant with $69.7 \%(23 / 33)$ prevalence, other strains identified were GII.2 and GII.12 each at 9.1\% (3/33); GI.9 strain at $6.1 \%$ (2/33); GII.6 and GII.10 strains each at (1/33), 3.0\% (Fig. 1a). Regarding classification by the RdRp gene, GII.Pe was most prevalent at $50 \%$ (17/34), followed by GII.P4 at 29\% (10/34). The other identified genotypes were GII.Pg at 9\% (3/34), GII.P7 at $6 \%(2 / 34)$, GII.P2 and GII.P17 each at (1/34), $3 \%$ (Fig. 1b). As shown in Fig. 2a, in 2013 and 2015 based on capsid gene, the predominant strain was GII.4 but interestingly this strain was not detected in the year 2014. Norovirus infection in 2014 was characterized by GII.12, GII.6 and GII.2 strains, however based on the RdRp; GII.Pe was detected in combination with GII.2.

Of the 23 identified GII.4 strains, 13 were identified on the Norovirus Genotyping Tool as phylogenetically related to the Sydney 2012 variant, and 10 were unassigned. The unassigned samples were queried in the NCBI database (Additional file 1: Table S1) and 9 samples had close identity to the Sydney 2012 variant isolated in South Africa while one had close identity to a variant isolated in Japan. Five of these nine GII.4 strains were closely related to GII/Hu/ZA/2012/GII.Pe-GII.4 Sydney 2012/Johannesburg 9814 (KJ710247.1). Their query coverage ranged from 95 to $97 \%$ and nucleotide identity was $98-99 \%$. The other 4 strains were closely related to the GII/Hu/ZAF/2013/ GII.Pe-GII.4 Sydney 2012/Cape Town (KR904238.1) with query coverage of

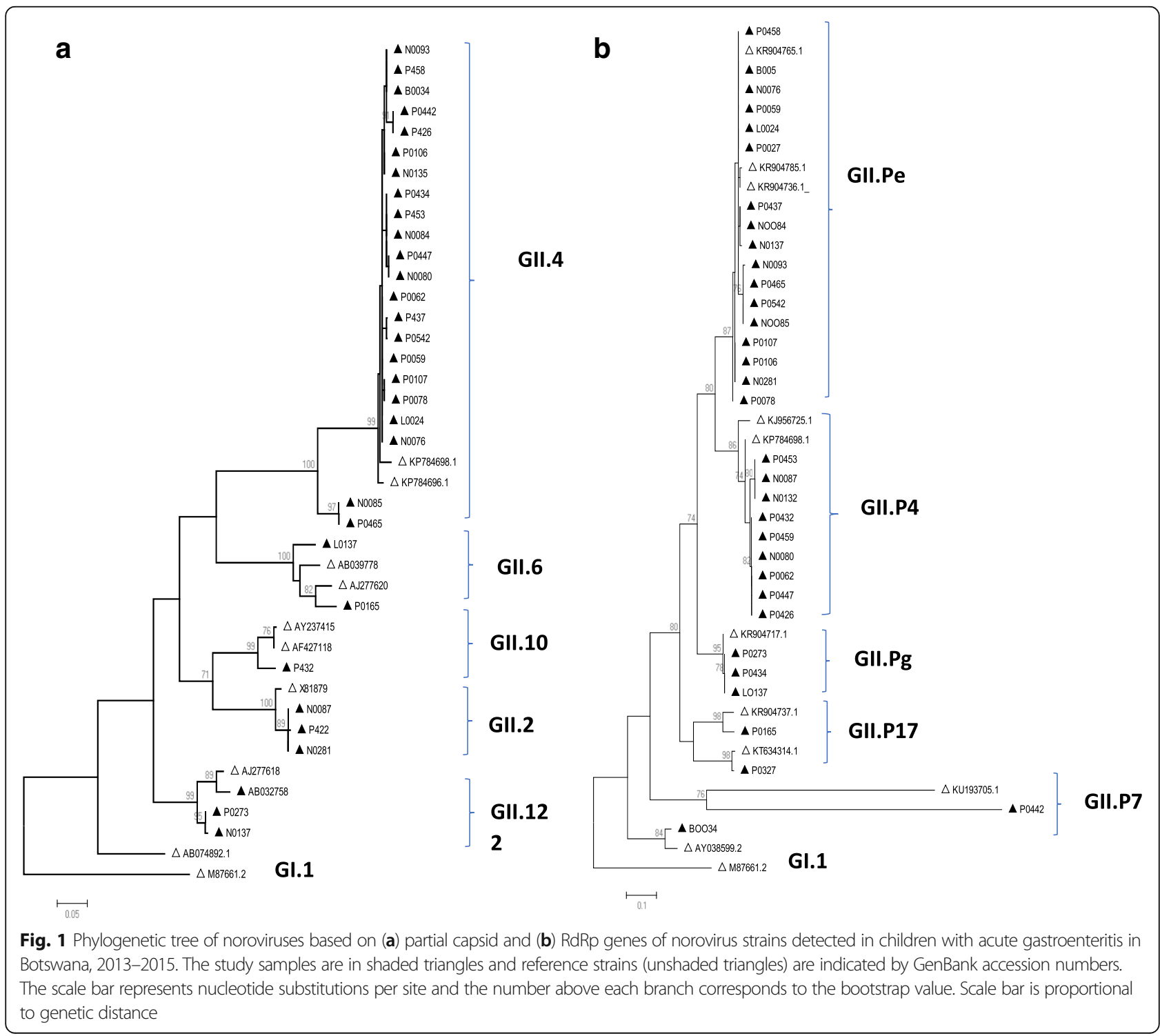



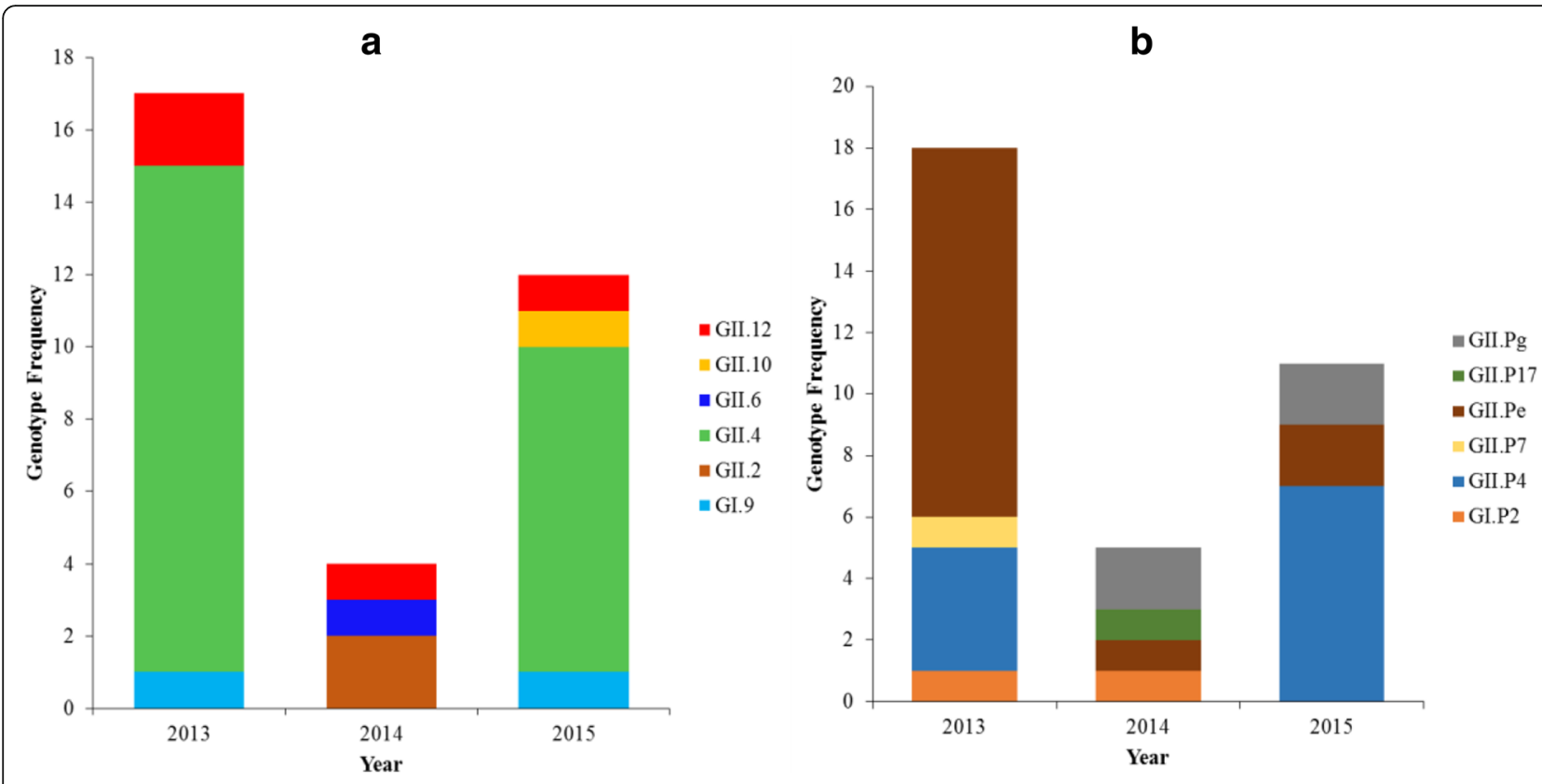

Fig. 2 Distribution of norovirus genotypes by year from Botswana, 2013-2015. a Capsid and b RNA dependent RNA polymerase

99-100\% and 95-99\% nucleotide identity. The last sample was similar to NV/Saitama T37Dgii/01/JP (AB112236.1) with 96\% query coverage and 95\% nucleotide identity, Additional file 1: Table S1. Based on the RdRp genotype sequences, in 2013 the GII.Pe strain was the most prevalent whereas in 2015, the GII.P4 was dominant, Fig. 2b. The GII.P4 strains were mainly New Orleans 2009 variants. Combined RdRp and capsid genotypes of 31 GII strains were determined resulting in 11 possible variants, of which 23/31 (67.7\%) were concordant between the two classification and 10/31 $(32.3 \%)$ were discrepant. These were GII.Pe/GII.4 at (36\%, $n=11 / 31) ; \quad$ GII.P4/GII.4 at $(26 \%, \quad n=8 / 31)$; followed by GII.Pe/GII.12; GII.Pg/GII.4; and GII.Pe/ GII.2 each at $(7 \%, n=2 / 31)$ and lastly; GII.P4/GII.10; GII.Pg/GII.12; GII.Pg/P2; GII.P2/GII.4; GII.P7/GII.4; GII.P2/GII.6 at $(3 \%, \mathrm{n}=1 / 31)$ each, Table 2 .

\section{Discussion}

Viral gastroenteritis remains an important cause of morbidity and mortality in the developing countries. Furthermore, with the considerable decline of rotavirus-associated diarrhoea in countries that have introduced the rotavirus vaccine, it's important to account for the high numbers of diarrhoea cases that are still seen. In this study, we report a possible shift in the variant distribution of norovirus infections in Botswana. The prevalence of norovirus was found to be at $9.3 \%$ among children admitted with acute gastroenteritis at four health facilities in Botswana between July 2013 and December 2015. These facilities are distributed across the southern and northern regions of the country where more than $80 \%$ of the population resides. The prevalence estimate falls close to the regional average of $13.5 \%$ (range 0.8 to 25.5) [10] but lower than that of the previous study in Botswana at 24\% [19]. This may suggest a possible decline in the NoV infections in the last 10 years but not necessarily a reduction in the number of gastroenteritis cases. The prior study had a smaller sample size (collected over a 7 year period, $\sim 10$ samples per year) and did not only enrol children admitted to hospital. In the previous study, there was a high prevalence on norovirus and GII.4 and it is possible that this could have been due to outbreak of new GII.4 variant. There is over

Table 2 Norovirus polymerase and capsid genotypes obtained from faeces of children with gastroenteritis in Botswana, 20132015

\begin{tabular}{lll}
\hline Polymerase (RdRp) genotype & Capsid (VP1) genotype & Number (\%) \\
\hline Gll.Pe & Gll.4 & $11(36 \%)$ \\
Gll.P4 & Gll.4 & $8(26 \%)$ \\
Gll.Pg & Gll.4 & $2(7 \%)$ \\
Gll.Pe & Gll.12 & $2(7 \%)$ \\
Gll.Pe & Gll.2 & $2(7 \%)$ \\
Gll.P4 & Gll.10 & $1(3 \%)$ \\
GII.Pg & Gll.12 & $1(3 \%)$ \\
GII.Pg & Gll.2 & $1(3 \%)$ \\
GII.P2 & Gll.4 & $1(3 \%)$ \\
GII.P7 & Gll.4 & $1(3 \%)$ \\
GIl.P2 & Gll.6 & $1(3 \%)$ \\
\hline
\end{tabular}


ten-year gap between sample collection of the study and our study. In this study, we have increased the sample size by prospectively enrolling each child admitted to hospital, determined the seasonality and included more geographic areas to understand the current burden of norovirus in the country. Additionally, it is possible that this represents a shift in the aetiology of diarrhoea and that the children could be exposed to wider causes of gastroenteritis. A study that characterized the aetiology of infections in a diarrhoea outbreak that occurred in 2006 in Botswana, revealed diverse aetiology of infections, mainly due to Cryptosporidium parvum, Cryptosporidium homins and Escherichia coli, while viral pathogens contributed a smaller proportion [29]. We also found the high number of gastroenteritis cases in spring but with low norovirus prevalence, which may be indicative of a different cause for the gastroenteritis.

While the prevalence is not statistically significant across the years, there is an upward trend that was observed between 2013 and 2015. Although causality cannot be ascertained at this point, it is possible that this significant increase could be attributable to the success of the rotavirus vaccine, which was introduced in 2012 [22]. Studies from other regions have shown that where rotavirus vaccines are used on a large scale, there is an increase in the proportion of norovirus cases [10, 30]. By 2014 rotavirus vaccine rollout or coverage in Botswana among the under 2 years was reported to be over $70 \%$, a move that may have significantly reduced rotavirus related gastroenteritis [22]. The norovirus infection among the age categories was not statistically significant though there was a trend of higher prevalence in the age category of 7 to 12 months. This trend is consistent with some of the published studies, which showed that norovirus infections were more common in the 7 to 12 months age groups [16, 31, 32]. One explanation given is that this is a period where kids begin to interact more actively with their environment and can be easily exposed to norovirus [5, 32]. Furthermore, this is also a period when solid foods are introduced and children are often weaned from breastfeeding and in regions where clean water is not always available, there could be increased exposure to contaminated feeds [33]. Norovirus infections from this study were detected in most parts of the year with exception of April, June and November for all the three years of the study. Nonetheless, a higher proportion of infections occurred in the wet months than in the dry season. While studies from some regions show distinct patterns in norovirus seasonality $[34,35]$, results from African countries have not shown well-defined seasonal patterns. A study by Mans et al. in South Africa, which borders Botswana on the southern side, has shown a comparable norovirus seasonal pattern with infections occurring in the spring and early summer [16]. In some countries like Burkina Faso and Nigeria norovirus infections peaked in the dry season [31, 36], whereas in countries like Malawi and Morocco norovirus infections peaked in the wet seasons [37-39]. A study in Tunisia did not show any clear seasonal peaks [40]. Several factors have been suggested to contribute to the seasonality of norovirus infection and they include rainfall, population density and human behaviour [10], and as these are varied across African countries they could perhaps explain the discrepancy observed in the seasonality of norovirus infection. Additionally, there is a disparity on the prevalence of norovirus infections by health facility. A small proportion of norovirus cases were detected in Letsholathebe II Memorial Hospital and one explanation is that the health facilities are in geographically distinct areas with different livelihoods. While there is a lot of movement between the other three locations, Letsholathebe is situated in a village with less interaction than the other three.

Consistent with other RNA viruses, noroviruses are genetically diverse even within genogroups. The results from this study showed that GII was the most commonly detected strain. These findings are consistent with those of previous reports from Botswana and elsewhere $[5,19]$. We also found a dominance of the GII.4 strains. While this study detected GII.4 variants Sydney 2012 based on capsid gene and New Orleans 2009 based on the RdRp gene, a previous study in Botswana reported more diverse GII.4 variants like Farmington Hills 2007, Hunter 2004, Yerseke 2006a and New Orleans 2009 [19]. A possible shift in GII.4 variant distribution could be attributed to the high mutation rate and evolution of norovirus strains leading to introduction of novel strains. The analysis of combined capsid and RdRp genes also showed diverse norovirus infections. GII.Pe/GII.4 Sydney 2012 was the most prevalent. These results suggest the possibility of recombination between open reading frames ORF1/ORF2 overlap region. We observed several GII.4 variants that were unassigned $(10 / 23)$ by the Norovirus Genotyping tool, but were resolved by querying the NCBI database (Additional file 1: Table S1). Most of these strains showed between 95 and 100\% identity with Sydney 2012 strains isolated in neighbouring South Africa [17]. The most common combined capsid and RdRp was the GII.Pe/GII.4 Sydney 2012, these two genotypes were detected in major outbreaks in Australia [41], and thereafter became the predominant species. Some of these strains have been described before $[8,41]$ and some are possible novel recombinants. In this study the combined genotypes were determined from separate $\mathrm{RdRp}$ and capsid amplicons, as such they could also represent coinfections and not recombinant strains. In 2014, GII.Pe was detected in combination with GII.2. To confirm recombinant strains the RdRp and capsid sequences will need to 
be determined from a single amplicon overlapping the ORF1/ORF2 junction $[8,41]$, a subject for further study.

\section{Conclusions}

In conclusion, this study has shown that norovirus strains circulating in Botswana are diverse and that there is a trend toward increased proportion of norovirus positive cases in the three years following rotavirus vaccine introduction. These infections increased in the wet season. The GII.4 strain showed a possible shift in the variant distribution in the country.

\section{Additional file}

Additional file 1: Table S1. Gll.4 Variants and similarity to published sequences. Query data from NCBI database of previously unassigned samples. (DOCX $24 \mathrm{~kb}$ )

\section{Abbreviations}

HRDC: Health Research and Development Council; MEGA: Molecular Evolutionary Genetic Analysis; NoV: Norovirus; ORF: Open Reading Frame; RdRp: RNA-dependant RNA polymerase; RT-PCR: Real-Time Polymerase Chain Reaction

\section{Acknowledgements}

We thank the National Health Laboratory and Botswana Harvard AIDS Institute Partnership for use of the laboratories. The sponsors had no role in the study design, collection of data and results interpretation.

\section{Funding}

This study was funded by the Grand Challenges Canada and by the Botswana International University of Science and Technology (Department of Biological Sciences and Biotechnology). The funding bodies had no role in the design of the study, collection of samples, analysis and interpretation of data and in writing the manuscript.

\section{Availability of data and materials}

All data generated or analysed during this study are included in this published article. The sequences generated have been submitted to GeneBank with accession numbers MF817977 to MF818009 for RdRp gene sequences and MF920049 to MF920478 for capsid gene sequences.

\section{Authors' contributions}

Conception and design of study, KM, LPK, SM, KL, DMG acquisition of data, KM, LPK, SM, KL, DMG analysis and/or interpretation of data, KM, LPK, SM drafted the manuscript, KM revised the manuscript critically for importan intellectual content: KM, LPK, SM, KL, DMG approved the version of the manuscript to be published: KM, LPK, SM, KL, DMG. All authors read and approved the final manuscript.

\section{Ethics approval and consent to participate}

Written informed consent was obtained from all parents and guardians of the children that were enrolled in this study. Ethical approval for the study, to perform molecular analyses on the samples was obtained from Botswana's institutional review board, the Health Research and Development Council (HRDC). Furthermore, permission to collect data, samples from patients and subsequent analysis was sought from HRDC, McMaster University and University of Pennsylvania as reported in the previous study [22]. This study was conducted according to the principles expressed in the Declaration of Helsinki.

\section{Competing interests}

The authors declare that they have no competing interests.

\section{Publisher's Note}

Springer Nature remains neutral with regard to jurisdictional claims in published maps and institutional affiliations.

\section{Author details}

${ }^{1}$ Department of Biological Sciences and Biotechnology, Botswana International University of Science and Technology, Private Bag, 16 Palapye, Botswana. ${ }^{2}$ Botswana Harvard AIDS Institute Partnership, Gaborone, Botswana. ${ }^{3}$ Harvard T.H Chan School of Public Health, Boston, MA, USA. ${ }^{4}$ Botswana-UPenn Partnership, Gaborone, Botswana. ${ }^{5}$ Department of Pathology, University of British Columbia, Vancouver, Canada.

Received: 3 November 2017 Accepted: 21 May 2018

Published online: 30 May 2018

References

1. Bartnicki E, Cunha JB, Kolawole AO, Wobus CE. Recent advances in understanding noroviruses. F1000Res. 2017;6:79

2. Karst SM. Pathogenesis of noroviruses, emerging RNA viruses. Viruses. 2010; 2(3):748-81.

3. Alam A, Qureshi SA, Vinje J, Zaidi A. Genetic characterization of norovirus strains in hospitalized children from Pakistan. J Med Virol. 2016:88(2):216-23.

4. Kong BH, Lee SG, Han SH, Jin JY, Jheong WH, Paik SY. Development of enhanced primer sets for detection of norovirus. Biomed Res Int. 2015:2015: 103052

5. Vicentini F, Denadai W, Gomes YM, Rose TL, Ferreira MS, Le Moullac-Vaidye B, Le Pendu J, Leite JP, Miagostovich MP, Spano LC. Molecular characterization of noroviruses and HBGA from infected Quilombola children in Espirito Santo state, Brazil. PLoS One. 2013;8(7):e69348.

6. Ayukekbong JA, Mesumbe HN, Oyero OG, Lindh M, Bergstrom T. Role of noroviruses as aetiological agents of diarrhoea in developing countries. J Gen Virol. 2015;96(8):1983-99.

7. Lekana-Douki SE, Kombila-Koumavor C, Nkoghe D, Drosten C, Drexler JF, Leroy EM. Molecular epidemiology of enteric viruses and genotyping of rotavirus a, adenovirus and astrovirus among children under 5 years old in Gabon. Int J Infect Dis. 2015;18(15):00070-3.

8. Takanashi S, Wang Q, Chen N, Shen Q, Jung K, Zhang Z, Yokoyama M, Lindesmith LC, Baric RS, Saif L. Characterization of emerging GII.G/Gll.12 noroviruses from a gastroenteritis outbreak in the United States in 2010 Clin Microbiol. 2011;49(9):3234-44.

9. Atmar RL, Bernstein DI, Harro CD, Al-Ibrahim MS, Chen WH, Ferreira J, Estes MK Graham DY, Opekun AR, Richardson C, et al. Norovirus vaccine against experimental human Norwalk virus illness. N Engl J Med. 2011;365(23):2178-87.

10. Mans J, Armah GE, Steele AD, Taylor MB. Norovirus epidemiology in Africa: review. PLoS One. 2016;11(4):e0146280.

11. Munjita SM. Current status of norovirus infections in children in sub-Saharan Africa. J Trop Med. 2015;2015(10):309648.

12. Park S, Jung J, Oh S, Jung H, Oh Y, Cho S, Cho S, Cho S, Park H, Jo N, et al. Characterization of norovirus infections in Seoul, Korea. Microbiol Immunol. 2012:56(10):700-7.

13. Gomez-Santiago F, Ribas-Aparicio RM, Garcia-Lozano H. Molecular characterization of human calicivirus associated with acute diarrheal disease in Mexican children. Virol J. 2012;9(54):54.

14. Thorne LG, Goodfellow IG. Norovirus gene expression and replication. J Gen Virol. 2014:95(2):278-91.

15. Ouedraogo N, Kaplon J, Bonkoungou IJ, Traore AS, Pothier P, Barro N, Ambert-Balay K. Prevalence and genetic diversity of enteric viruses in children with diarrhea in Ouagadougou, Burkina Faso. PLoS One. 2016;11(4): e0153652

16. Mans J, de Villiers JC, du Plessis NM, Avenant T, Taylor MB. Emerging norovirus Gll.4 2008 variant detected in hospitalised paediatric patients in South Africa. J Clin Virol. 2010;49(4):258-64.

17. Mans J, Murray TY, Taylor MB. Novel norovirus recombinants detected in South Africa. Virol J. 2014:11(168):11-168.

18. Hoa Tran TN, Trainor E, Nakagomi T, Cunliffe NA, Nakagomi O. Molecular epidemiology of noroviruses associated with acute sporadic gastroenteritis in children: global distribution of genogroups, genotypes and Gll.4 variants. J Clin Virol. 2013:56(3):185-93.

19. Mattison K, Sebunya TK, Shukla A, Noliwe LN, Bidawid S. Molecular detection and characterization of noroviruses from children in Botswana. J Med Virol. 2010;82(2):321-4. 
20. Creek TL, Kim A, Lu L, Bowen A, Masunge J, Arvelo W, Smit M, Mach O, Legwaila K, Motswere C, et al. Hospitalization and mortality among primarily nonbreastfed children during a large outbreak of diarrhea and malnutrition in Botswana, 2006. J AIDS (1999). 2010;53(1):14-9.

21. Welch $H$, Steenhoff AP, Chakalisa U, Arscott-Mills T, Mazhani L, Mokomane M, Foster-Fabiano S, Wirth KE, Skinn A, Pernica JM, et al. Hospital-based surveillance for rotavirus gastroenteritis using molecular testing and immunoassay during the 2011 season in Botswana. Pediatr Infect Dis J. 2013;32(5):570-2.

22. Enane LA, Gastanaduy PA, Goldfarb DM, Pernica JM, Mokomane M, Moorad B, Masole L, Tate JE, Parashar UD, Steenhoff AP. Impact of rotavirus vaccination on hospitalizations and deaths from childhood gastroenteritis in Botswana. Clin Infect Dis. 2016;62(2):S168-74.

23. Bucardo F, Reyes $Y$, Svensson L, Nordgren J. Predominance of norovirus and sapovirus in Nicaragua after implementation of universal rotavirus vaccination. PLoS One. 2014;9(5):e98201.

24. Goldfarb DM, Steenhoff AP, Pernica JM, Chong S, Luinstra K, Mokomane M, Mazhani L, Quaye I, Goercke I, Mahony J, et al. Evaluation of anatomically designed flocked rectal swabs for molecular detection of enteric pathogens in children admitted to hospital with severe gastroenteritis in Botswana. J Clin Microbiol. 2014;52(11):3922-7.

25. Kojima S, Kageyama T, Fukushi S, Hoshino FB, Shinohara M, Uchida K, Natori K, Takeda N, Katayama K. Genogroup-specific PCR primers for detection of Norwalk-like viruses. J Virol Meth. 2002;100(1-2):107-14.

26. Vinje J, Koopmans MP. Molecular detection and epidemiology of small round-structured viruses in outbreaks of gastroenteritis in the Netherlands. J Infect Dis. 1996;174(3):610-5.

27. Kroneman A, Vennema H, Deforche K, $v$ d Avoort H, Penaranda S, Oberste MS, Vinje J, Koopmans M. An automated genotyping tool for enteroviruses and noroviruses. J Clin Virol. 2011;51(2):121-5.

28. Tamura K, Stecher G, Peterson D, Filipski A, Kumar S. MEGA6: molecular evolutionary genetics analysis version 6.0. Mol Biol Evol. 2013;30(12): 2725-9.

29. Mach O, Lu L, Creek T, Bowen A, Arvelo W, Smit M, Masunge J, Brennan M, Handzel T. Population-based study of a widespread outbreak of diarrhea associated with increased mortality and malnutrition in Botswana, Januarymarch, 2006. Am J Trop Med Hyg. 2009;80(5):812-8.

30. Karst SM, Tibbetts SA. Recent advances in understanding norovirus pathogenesis. J Med Virol. 2016;88(11):1837-43.

31. Oluwatoyin Japhet M, Adeyemi Adesina O, Famurewa O, Svensson L, Nordgren J. Molecular epidemiology of rotavirus and norovirus in Ile-lfe, Nigeria: high prevalence of G12P[8] rotavirus strains and detection of a rare norovirus genotype. J Med Virol. 2012;84(9):1489-96.

32. Imade PE, Eghafona NO. Viral agents of diarrhea in young children in two primary health centers in Edo state, Nigeria. Int J Microbiol. 2015;2015(10):685821.

33. Lamberti LM, Fischer Walker CL, Noiman A, Victora C, Black RE. Breastfeeding and the risk for diarrhea morbidity and mortality. BMC Public Health. 2011;11(3):S15

34. Kim JS, Kim HS, Hyun J, Kim HS, Song W. Molecular epidemiology of human norovirus in Korea in 2013. Biomed Res Int. 2015;2015:468304.

35. Lee SG, Cho HG, Paik SY. Molecular epidemiology of norovirus in South Korea. BMB Rep. 2015;48(2):61-7.

36. Nordgren J, Nitiema LW, Ouermi D, Simpore J, Svensson L. Host genetic factors affect susceptibility to norovirus infections in Burkina Faso. PLoS One. 2013;8(7):e69557.

37. Dove W, Cunliffe NA, Gondwe JS, Broadhead RL, Molyneux ME, Nakagomi $\mathrm{O}$, Hart CA. Detection and characterization of human caliciviruses in hospitalized children with acute gastroenteritis in Blantyre, Malawi. J Med Virol. 2005;77(4):522-7.

38. Trainor E, Lopman B, Iturriza-Gomara M, Dove W, Ngwira B, Nakagomi O, Nakagomi T, Parashar U, Cunliffe N. Detection and molecular characterisation of noroviruses in hospitalised children in Malawi, 1997-2007. J Med Virol. 2013;85(7):1299-306.

39. El Qazoui M, Oumzil H, Baassi L, El Omari N, Sadki K, Amzazi S, Benhafid M, El Aouad R. Rotavirus and norovirus infections among acute gastroenteritis children in Morocco. BMC Infect Dis. 2014;14(300): 1471-2334.

40. Sdiri-Loulizi K, Ambert-Balay K, Gharbi-Khelifi H, Sakly N, Hassine M, Chouchane S, Guediche MN, Pothier P, Aouni M. Molecular epidemiology of norovirus gastroenteritis investigated using samples collected from children in Tunisia during a four-year period: detection of the norovirus variant GGll.4 hunter as early as January 2003. J Clin Microbiol. 2009;47(2):421-9.

41. Martella V, Medici MC, De Grazia S, Tummolo F, Calderaro A, Bonura F, Saporito L, Terio V, Catella C, Lanave G, et al. Evidence for recombination between pandemic Gll.4 norovirus strains New Orleans 2009 and Sydney 2012. J Clin Microbiol. 2013;51(11):3855-7.

\section{Ready to submit your research? Choose BMC and benefit from:}

- fast, convenient online submission

- thorough peer review by experienced researchers in your field

- rapid publication on acceptance

- support for research data, including large and complex data types

- gold Open Access which fosters wider collaboration and increased citations

- maximum visibility for your research: over $100 \mathrm{M}$ website views per year

At BMC, research is always in progress.

Learn more biomedcentral.com/submissions 